\title{
Origen y fuentes históricas de las fórmulas de cortesía y tratamientos habituales en la sociedad española en la vida social y oficial
}

Origin and historical sources of the formulas of courtesy and habitual treatments in the Spanish society in the social and official life

\author{
Fernando Ramos Fernández ${ }^{1}$ \\ Universidad de Vigo \\ ferramos@telefonica.net
}

Recepción: 29.12.2016 Revisión: 30.12.2016 Aceptación: 30.12.2016 Publicación: 15.01.2017

\section{Resumen (máximo 300 palabras)}

Recorrido histórico de la mano de los más autorizados "prohombres" que se han ocupado de este fenómeno, para concluir com la esperanza de que al recuperar el conocimiento de este patrimônio, volvamos, em la medida de lo posible, a introducir su uso

Palabras claves: etiqueta, cortesia, buenas maneras, historia

\section{Abstract (maximun 300 words)}

This paper es a historical overwiew of the hand of the mos authoritative "notables" who have deal with this phenomenon, concluding wit the hope that retrievins the knowledge of this heritage back as far as possible to introduce its use.

Keywords: etiquette, courtesy, good manners, history

\section{Sumario}

1. Introducción

2. Desarrollo

3. Conclusiones

4. Bibliografía

\footnotetext{
${ }^{1}$ Profesor Titular de la Universidad de Vigo
} 


\section{Summary \\ 1. Introduction \\ 2. Exposition \\ 3. Conclusion \\ 4. Bibliography}

\section{Orígenes e historia de las fórmulas tradicionales de cortesía}

Seguimos a Don Américo Castro (1983: 83-124) para entender el origen de las viejas fórmulas de la cortesía española, hoy en gran parte perdidas, cuando no combatidas por el mal ejemplo de la clase política, para quien estas muestras de civilidad, extendidas por toda España, pero que en Galicia han tenido siempre matices propios, tiene estrecha relación con el contacto con el mundo islámico.

Entre las apostillas o frases de cierre que usamos de modo cotidiano, incluso por aquellas personas nada religiosas, es especialmente común "Así Dios o queira" (en Galicia se suele decir Dios y no Deus en castellano, como curiosa muestra de respeto, lo mismo que Rey y no Rei, al escribir, cosa que debemos desterrar y usas nuestro idioma propio). Pero es frecuente escuchar "Si Dios quiere", o "Si quiere Dios", "Quiera Dios", "Hasta mañana, si Dios quiere", "A ver si quiere Dios que llueva", o al contrario "Dios no lo quiera".

Parece, al pronto, que tal frase procede de la piedad o religiosidad católica, tan aferrada en España, aunque la presencia de ojalá, "wa sa'a-I-lah", "quiera Dios", nos hace ver su origen. Se trata de otra seudomorfosis (como almogávar-corredor), que hoy aparece ya con sentido cristiano." La prueba de ello es que no se puede traducir literalmente a ninguna otra lengua europea, "Hasta mañana, si Dios quiere", que para multitud de españoles es algo natural, que dicen sin énfasis religioso de ninguna clase. De un modo general me parece que puede pensarse que los españoles usan o han usado el nombre de Dios más que los otros pueblos románicos; compárese elartículo Dios en el Diccionario de la Academia Española con el correspondiente del Diccionario francés de Littré, y se entenderá lo que quiero decir. Creo que, en muchos casos, tras el Dios cristiano vibra el eco del Allah, insiste en autor de "España en su historia. Cristianos Moros y Judíos".

En nuestros usos sociales, el nombre de Dios está presente de modo cotidiano, incluso en las gentes menos religiosas. En los agitados años que precedieron a la guerra civil, un dirigente anarquista se dirigía a sus compañeros advirtiendo que la disciplina del sindicato exigía "que todo el mundo abonara las cuotas ireligiosamente!". El arraigo es tan notable como su historia, ya en el siglo decían los mozárabes: "que Deus defenda, que Dios mantenga". Comenta Castro que el propio Menéndez Pidal subrayó aquella influencia en la fórmula para referirse tradicionalmente al Rey "Que Dios guarde".

No deja de ser curioso que siendo una de las advocaciones del Rey de España la de "Su Majestad Católica", y que el sucesor de Franco a título de Rey, Juan Carlos I, hubo de cumplir, entre otros requisitos, ser fiel hijo de la Iglesia, su heredero haya tratado de disimular el origen de su reinado con alguna medidas que ha sorprendido. Felipe VI no juró su cargo sobre la Biblia como hiciera su padre Juan Carlos a la muerte de Franco en 1975. 
Tampoco hubo una misa multimillonaria como entonces. Pero su primera visita fue al Papa. O sea, una de cal y otra de arena. Felipe VI ha dispuesto cumplir con la aconfesionalidad del Estado y ello lleva a algunos detalles que han podido pasar desapercibidos como el haya desaparecido aquella vieja fórmula según la cual en las invitaciones oficiales de Zarzuela se leía siempre en su comienzo: "Su Majestad el Rey que Dios guarde". Los consejeros de Felipe VI retiraron esa fórmula para atenerse estrictamente al Estado aconfesional que es como consta en la Constitución.

O sea, que en España Dios ya no guarda al Rey.

Pero la fórmula de que a cada uno le guarde Dios era frecuente entre las gentes sencillas del campo, con variantes como "Dios guarde a ustedes, caballeros", "Dios mantenga", o "A la paz de Dios". Se cree que este saludo es la traducción al lenguaje de los españoles la vieja fórmula árabe "Al-salñm 'alayk "(la paz sea contigo). Pero quizá olvidan la fórmula cristiana "Pax Domini sit vobíscum" (La paz del Señor sea con vosotros).

\section{Besar la mano como fórmula epistolar}

La pervivencia epistolar de concluir las cartas con "Beso a usted la mano" o "Quedo a sus pies" o la fórmula de cortesía: "Póngame a los pies de su señora" es otro de tantos usos de vieja cultura española:

Todavía en el siglo XIX las señoras despedían a los caballeros diciendo: "beso a usted la mano", y el señor correspondía con un "a los pies de usted, señora". En provincias en donde perdura la tradición más que en Madrid, todavía hay quien lo dice (se usaba hasta tiempos recientes). Dice Mariano José de Larra aún conocía la costumbre tradicional de besar el hijo la mano de su padre: Andaba siempre señor padre, que entonces no se llamaba papá, con la mano más besada que reliquia vieja (El casarse pronto y mal). Mas también entre musulmanes un hijo terminará una carta dirigida a su padre con la fórmula, "después de haber besado vuestra respetable mano"

Américo Castro, en su repaso a los usos de cortesía española a lo largo de nuestra historia, tan olvidada, rastrea todos aquellos ejemplos que os ofrezcan la suficiente perspectiva y en este sentido recuerda:

En una carta a Felipe n, en 1566, que se halla expuesta en la Hispanic Society de Nueva York, don. Luis de Requesens suscribe así su epístola: "De V. M. hechura, vasallo y criado que sus muy reales pies y manos besa". En el teatro español del siglo XVII es usual la fórmula "dadme los pies2, cuando el inferior quiere mostrar su gratitud reverente al rey: "Dadme, gran señor, los pies". En el Quijote (II, 16), Sancho Panza "besó los pies una y muchas veces" a don Diego de Miranda, cosa que ha parecido tan normal a los comentaristas, que la dejan sin explicar. Ya en el Poema del Cid, el héroe intenta en una ocasión besar los pies del rey Alfonso VI, y éste no lo permite: "Besad las manos, ca los pies no". Cuando Blanquerna, en el célebre libro de Ramon Llull, se despide de su padre para ir a vivir como un anacoreta, "de genollons, besa les mans e-ls peus a son pare" El que esa costumbre hubiera sido aprendida por los musulmanes en contacto con Bizancio, o con otra civilización, es ahora indiferente. Lo que importa es notar que los españoles cristianos la han tomado de los españoles musulmanes. La fórmula de vasallaje -besar la mano- no tiene relación con el feudalismo europeo, sino con la historia española. 
En la mesa, la costumbre de trazar la cruz sobre la hogaza de pan, lavarse las manos antes de comer o besar el pan que ha caído al suelo, muy frecuente en Galicia, tiene su origen en los refectorios de los monasterios. El pan es el cuerpo de Cristo transfigurado. Para tocarlo, las manos han de estar limpias, se debe besar cuando cae el suelo y se hace sobre él la señal de la Cruz. Antiguamente, cuando caía una hostia consagrada al suelo durante la misa, se cubría con un paño antes de recogerla.

\section{Otras fórmulas de cortesía}

Dice don Américo:

Al mostrar a una persona amiga un objeto de valor que nuevamente se posee, si aquélla lo elogia, lo correcto es decir: "Está a su disposición". Ha acontecido a veces que un extranjero, ignorante de que esas palabras son un mero rito, preguntara si de veras le ofrecían el objeto valioso, y ello ha creado más de una situación embarazosa.

Todas las cosas de nuestras vidas tienen su porqué. El ofrecimiento del propio hogar, la fórmula cortés "Esta es su casa" tiene un sentido que va más allá del mero ritualismo de otras culturas. Explica Don Américo que era musulmana la costumbre de decir: "ésta es su casa", a quien la visita por primera vez. Al marcharse el visitante se le dice: "Ya sabe que ha tomado posesión de su casa". En portugué se emplea la forma "Disponha da casa como se fosse sua, é urna casa a sua dísposicáo". En catalán: "Ha pres possessió de casa seva, aquí és a casa seva" y en Galicia: "Esta é a súa casa" o"Esta é a miña casa que agora é a súa"

Todo ello es herencia árabe: "Al-bayt baytak", (esta casa es tu casa), y los europeos se quedan asombrados al oír en Lisboa, Madrid o Barcelona que la casa que visitan por vez primera les pertenece, según nuestro famoso historiador.

En aquellos interminables viajes de la RENFE de antaño, cuando se viajaba con manta y fiambrera en cesta de mimbre era común practicar una de las más entrañables formas de cortesía ordinaria: invitar y compartir las viandas de que se dispusiera. Como subraya el recuento que tomamos como guía, al ir a comer o beber delante de alguien ajeno o desconocido, lo correcto era decir: “¿Usted gusta?”. Y hacerlo sinceramente.

Castro descubre que incluso exportamos estas costumbres:

En Italia, por los motivos antes dichos, se encuentra también un reflejo de la época española en la expresi6n "Vuol favorire?", que se oye, por ejemplo, en los trenes, cuando alguien se pone a comer ante otros viajeros que no comen. Quien conozca mejor que yo la literatura árabe de la Edad Media, encontrará fácilmente ejemplos de este uso familiar hoy para el mundo musulmán desde Marruecos hasta Siria.

Invitar a comer es una de las pruebas tradicionales de hidalguía, si alguien nos visita y llega esa hora. "Quédese connosco" se dice en Galicia. En portugués se dirá: "Voce é servido", o "¿Quer fazer-me companhia?·En catalán: "Sou servit?". Las respuestas son: "Que aproveche", o "De salud sirva" o "Que lle preste". En portugués y en gallego se responde: "Bon proveito".

Todas las cosas tienen un porqué un origen y una razón. Estas costumbres nuestras nacen y se expanden por las vías por las que circula nuestra herencia cultural y nuestro 
variado mestizaje. Por ejemplo, dice Castro que es evidentemente moruno el excusarse de dar limosna a un mendigo diciendo "perdone por Dios, Dios lo ampare, lo socorra, lo ayude", lo que equivale al árabe "Dios te dé, te ayude, te sostenga, te contente."

\section{Maldiciones, bendiciones e insultos}

Bendecir o maldecir es una práctica común en nosotros con parecida intensidad. Y se cree que es parte asimismo de las influencias orientales.Dice don Américo a este respecto.

No recuerdo que en ninguna lengua románica, fuera de las ibéricas, se hable, para bien o mal, de "la madre que te parió"; pueden decirse otras cosas, en italiano o francés, pero sin el "que te parió". Y he aquí que encuentro que el califa Al-Mansür (en Bagdad) dijo a alguien: "Sea para Dios la madre que te parió". Y hoy, 1.200 años después, dicen en España a una mujer bonita: "iBendita sea la madre que te parió!".

Punto especialmente delicado es mentar a la madre de manera ofensiva (lo mismo que a los muertos). Pero hay un matiz importante, la injuria, el insulto, tiene que ser "considerado socialmente como tal", hacerse de manera pública, con intención de ofender y que ese ataque al honor llegue al conocimiento del ofendido.

En España, en nuestros días, no existe una definición legal del honor. El Tribunal Constitucional se remite, en este sentido a los usos, valores y costumbres vigentes en la sociedad en un momento dado, por lo que encaja en la categoría de conceptos jurídicos indeterminados. Es evidente que el concepto del honor que tiene la sociedad española a finales del siglo XX no es el mismo que el que preocupaba a los ciudadanos de 1908, cuando llegó a presentarse en el Senado un Proyecto de Ley relativo a los delitos contra el honor y la supresión del (entonces frecuente) duelo.

La positivación normativa del honor y el derecho a la libertad de expresión, en cuanto que valores constitucionales, tiene su reflejo en el nuevo Código Penal, incorporando, por lo que se refiere al primero, un vigoroso cambio de sentido en cuanto al valor significativo del mismo. El honor forma parte de la dignidad de la persona en cuanto que valor ético-social frente a caducas concepciones propias del pasado. El honor se sitúa justamente en su concepto de estima propia y extraña.

A lo largo de los siglos XIX y XX, junto con las sucesivas reformas del Código Penal, el concepto jurídico de injuria se fue perfilando en función de los elementos que habrían de concurrir para que se incurriera en este supuesto y que esencialmente son:

El Fuero Real se consideraba injuria llamar a otro "gafo, sodomítico, cornudo, traidor o hereje" y la Ley VII de las Partidas advierte que, tanto en latín como en romance, "injuria es deshonra que es hecha o dicha a otro torcidamente, o despreciamiento del, y como quiera que muchas son de deshonra, pero todas descienden de dos raíces. La primera es de palabra y la segunda de hecho".

En el Código Penal de 1822 se define la injuria (artículo 703) como "todo acto hecho y toda palabra dicha con intención de deshonrar, afrentar, envilecer, desacreditar, hacer odiosa, despreciable o sospechosa, o mofar o poner en ridículo a otra persona, siempre que efectivamente el acto hecho o la palabra dicha, sean bastante para poder causar alguno de estos efectos en la opinión común o en la más generalmente recibida entre las gentes del pueblo donde se cometa el delito. También es injuria el remitir o hacer rehusar la honra o dar 
la señal de respeto que según la ley se debe a una persona, cuando se omite o rehúsa con la intención sobredicha".

La definición legal de la injuria no ha variado en unos 150 años y se ha quedado a merced de la jurisprudencia que, de modo contundente, optó por el análisis del ánimus iniuriandi como eje central del debate. En todo caso, el delito de injuria es un delito doloso, que exige siempre conocimiento y voluntad de la acción ejecutada o de la expresión proferida ${ }^{2}$.

\section{La cortesía reglamentada: Viejos y nuevos manuales de urbanidad}

Los tradicionales manuales de urbanidad y buenas maneras, vigentes y de mucho uso en España desde finales del siglo XIX hasta poco más de los años sesenta del pasado siglo, vistos desde nuestra perspectiva, presentan dos coincidencias reseñables: Por una parte, eran prontuarios con fórmulas -con frecuencia de catecismo civil- donde por medio de preguntas y respuestas se explicaba cómo comportarse correctamente en todas las circunstancias posibles de la vida social. Pero por otro lado, con no menos insistencia, enseñaban que la sociedad se divide en estratos y que los de abajo deben mostrar respeto a los de arriba, en tanto éstos debían ser condescendientes con los inferiores, desde su elevada posición. Este tipo de manuales no se ajustaba a un sólo modelo. Los había muy genéricos, otros eran más específicos, para un determinado colectivo o grupo social; estaban los editados por instituciones religiosas o que surgían en función de los cambios políticos habidos en el país, como el famoso "El Niño republicano", antecedente de la "Educación para la ciudadanía", aunque menos sesgado que algunas de las obras editadas al amparo de la política del gobierno de José Luis Rodríguez Zapatero, durante su etapa de presidente.

Uno de los últimos autores de un manual, clásico de Urbanidad fue Emilio Alonso Burgos, quien en 1959 edita "Cortesía Juvenil", en Salamanca, el libro de cabecera de educación urbana de los colegios salesianos de España.

El manual más antiguo que yo conozco, de autor anónimo está datado en 1837 y se titula: "El hombre fino al gusto del día. 3a Edición. "Traducido del francés al castellano por D. Mariano de Rentería y Fría. Aumentada con las reglas de educación y decoro para señoras. Imprenta del Colegio de Sordomudos, Madrid". Sánchez Moreno publica en 1925 su "Tratado práctico de etiqueta y distinción social", en la Editorial Cultura de Barcelona. La obra de Pilar

\footnotetext{
${ }^{2}$ Según el artículo $210 \mathrm{CP}$ : el acusado de injuria quedará exento de responsabilidad No existen las injurias culposas en el actual Código Penal probando la verdad de las imputaciones cuando éstas se dirijan contra funcionarios públicos sobre hechos concernientes al ejercicio de sus cargos o referidos a la comisión de faltas penales o de infracciones administrativas. El acusado será absuelto si puede probar la veracidad de las imputaciones. Los servidores de la función pública están más expuestos al ejercicio de la crítica que los ciudadanos de a pie.

La introducción de la "exceptio veritatis", aplicable al delito de injurias, en el caso de los funcionarios públicos es un hito diferenciador en nuestro sistema penal. La demostración de la verdad de las imputaciones, determinante en la condena o absolución del acusado, se restringe a los funcionarios públicos, siempre que correspondan a hechos relacionados con el ejercicio de sus cargos. Una parte de la doctrina considera que el planteamiento inicial de esta eximente es muy estrecha y que se precisa que con el tiempo, la jurisprudencia amplíe e ilustre su contenido.

La inclusión relativa a los funcionarios públicos, en el sentido de que las injurias dirigidas contra sus personas quedarán exentas de responsabilidad probando la veracidad de las imputaciones ha sido muy criticada por parte de quienes entienden que la protección penal de este derecho debe extenderse como garantía a todas las personas, sin atender a sus condición.
} 
Pascual Sanjuán, "Resumen de Urbanidad para las niñas" es, en realidad anterior, se publicó en 1920, pero sus consejos no son de carácter general, sino específicamente para el adolescente público femenino. Más conocida y todavía usado es la "Enciclopedia de la educación y mundología", de Editorial de Gassó Hermanos, que se publica en Barcelona en 1957 por parte de Antonio Armenteras. Gertrud Oheim publica en 1965 el "ABC de la etiqueta moderna". Círculo de Lectores, Madrid.

En contra de lo que pudiera pensarse, se han seguido publicando libros sobre urbanidad. Son frecuentes lo que se refieren a las buenas maneras, como el Manual de Angel Amable, que el Círculo de Lectores lanzó en 1992 y que se complementa con el clásico "Las buenas maneras", que Editorial Galaixa de Vigo reeeditó en 1992 al escritor Eduardo Blanco Amor.

En nuestros tiempos se suceden obras como: La etiqueta hoy. Como ir por la vida con seguridad y estilo. Ediciones Acervo, Barcelona, de Natalie Devalls, de 1995; o Manual de cortesía y convivencia, de Fernando Díaz Plaja, editado en 1996 en Oviedo por Nobel.

Además, es frecuente que se recuperen libros clásicos de consejas y recomendaciones, como "El arte de la prudencia", de Baltasar Gracián, edición da José Ignacio Díaz Fernández. Ediciones Temas de hoy (vigésima edición), Madrid, año 2002, o el famoso tratado del Duque de Camposol: "Código de etiqueta y distinción social". Editorial Estudio, Madrid, en fecha no determinada.

Y para clásico, el "Debret". "Nuevo tratado de Etiqueta y reglas sociales", de varios autores (edición española, que Edaf publica en 1984). Camilo López escribe "El libro del saber estar. La urbanidad y los usos sociales", que aparece en 1993 y edita Plaza y Janés en Barcelona. Son especialmente interesantes para estudio dos libros de Amado de Miguel "Cien años de urbanidad. Crítica de las costumbres de la vida española". Planeta, Barcelona (1991) y el libro del mismo autor, cuatro años después "La España de nuestros abuelos. Historia íntima de una época", de Espasa hoy, Madrid. Tampoco podemos olvidar en este recuento un libro especialmente entrañable, publicado en 1990, poco antes de morir, por el doctor Juan Antonio Vallejo Nágera: "Aprender a hablar en público".

Y no hemos de dejar fuera, por su fina ironía contracultural entonces y ahora, y pese a su tono sarcástico y burlón, el libro "Curso completo de gramática Parda. Dividido en quince lecciones en las que se dan reglas para que cualquiera pueda vivir sin tener necesidad de trabajar. Por el Bachiller Cantaclaro, publícala D. Ramón Soler. Madrid, 1865. Librería de la Viuda e Hijos de Don José Cuesta, Calle Carretas, núm.9".

Obispados, parroquias y curas diversos editaron en España durante la primera mitad del siglo XX toda clase de prontuarios donde mezclaban consejos religiosos con normas de conducta social, y hasta sanitarias e higiénicas, vistos obviamente desde la doctrina más rigurosa del nacional-catolicismo. Una joya, rara de encontrar, pero que el magisterio español tuvo que aprender y manejar son las "Normas de decencia cristiana", de la Comisión Episcopal de Ortodoxia y Moralidad, publicas por el Secretariado del Episcopado Español en Madrid en 1962.

Al igual que los imanes ortodoxos del Islam, el episcopado español recomendaba en su norma 123 del prontuario que citamos: 
"Deben evitarse los baños mixtos (individuos de distintos sexos), que entrañan casi siempre ocasión próxima de pecado y de escándalo, por muchas precauciones que se tomen y más, si cabe, en las piscinas, donde lo reducido del espacio y la aglomeración de personas hacen más próximo el peligro. Ni se atenúa porque las piscinas sean de propiedad particular y aun familiares".

Esta regla solamente admitía una excepción, con matices, las piscinas infantiles, "siempre que los niños no hayan llegado al uso de razón".

\section{El manual por excelencia: El hombre fino}

Sin duda, de todos los manuales de este tipo, el más completo puede ser el ya citado "El hombre fino", de 1837. En su portada se puede leer todo esto:

"El hombre fino al gusto del día. Manual Completo de Cortesía Urbanidad y Buen Tono, con las reglas, aplicaciones y ejemplos del Arte de presentarse y conducirse en toda clase de reuniones, visitas, etc.; en el que se enseña la etiqueta y ceremonial que la sensatez y la costumbre han establecido; con la Guía del tocador y un tratado del Arte ciusoria. Traducción del francés al castellano por Don Mariano de Rementeria y Fica. Tercera Edición. Aumentada con las reglas de Educación y Decoro para señoras. Madrid: 1837. Imprenta del Colegio de Sordo-mudos. Se hallará en la librería de Cuesta, frente a las Cobachuelas".

El sumario detalla los contenidos del libro e incluye: el hombre de gusto en casa, el trato con sus iguales, en casa de los superiores, de los artistas, en una tertulia, en el teatro, en el baile, en la boda, en la mesa, en la visita, en el viaje...Y además comprende recomendamos sobre: tocador, corbata, guantes, equitación y por último reglas y axiomas morales sobre el espíritu de la sociedad.

Algunos consejos son realmente curiosos y reflejan la hipocresía de un tiempo pasado en la sociedad española. Con respecto al matrimonio señala:

"Hay matrimonios de amor y de especulación. Si vuestra elección la ha decidido más bien la dote de una joven que su hermosura, encubrid cuidadosamente el motivo de vuestra determinación, aparentad para con la novia un amor que el tiempo producirá al cabo en vuestro corazón". No os pongáis a regatear como sucede a menudo sobre el precio de aquella que buscáis, dejad a amigos seguros y discretos el cuidado de las condiciones del contrato".

En el libro sobre cómo deben presentarse las niñas bien educadas Pilar Pascual Sanjuán ("Resumen de Urbanidad para las niñas) nos enseñan que lo correcto es hacerlo así: "Una servidora de usted o simplemente servidora de usted (según los casos), la que tiene el gusto (o el honor) e hablar a usted, etcétera...." En esta obra, se distinguen varias situaciones desde la urbanidad en general y el trato, bien con superiores o inferiores, la escuela, la mesa, el especial respeto a las personas con dignidad. La verdad es que, pese al tiempo transcurrido, alguno de sus consejos sobre la cortesía social no están tan pasados de moda.

\section{Los consejos del duque de Camposol para todo}


Entre otras muchas cosas, en su "Código de etiqueta y distinción social", el duque de Camposol os dice:

"Los que visiten una oficina pública, bien sea en los despachos, o utilizando las ventanillas, deberán descubrirse, formulando sus preguntas en tono correcto y no exigiendo del funcionario con quien se relacionen más datos que los que éste pueda darles por razones reglamentarias o de obligada delicadeza. La altanería, las amenazas o cualquier otro género de coacción, son vejámenes intolerables para los funcionarios y demuestran una pésima educación en quien los emplea, pudiendo dar lugar a que el funcionario agraviado en el ejercicio de su cargo impida la estancia en el local del despacho a la persona que tan mal se comporte.

La entrada en un departamento u oficina pública no ha de realizarse sin que previamente se pida permiso, debiendo permanecer el visitante en pie, hasta tanto que se le ofrezca asiento y haciéndolo a distancia de la mesa donde haya papeles o libros abiertos, cuya lectura sería siempre imprudente, antirreglamentaria y hasta punible.

En las tiendas seremos correctos con los dependientes, y jamás abusaremos de la tolerancia que forzosamente han de tener éstos con el público, para hacerles revolver el establecimiento entero, saliendo luego sin haber adquirido objeto alguno.

En los cafés nos comportaremos como personas educadas, demandando perdón a las personas que sufran una molestia de nuestra parte. Si concurrimos invitados por alguna persona dejaremos que ésta pague, apreciando de tal forma su deferencia. Nada más ridículo que esos pugilatos tan corrientes en los cafés y cervecerías, en los que dos personas discuten sobre quien ha de pagar, cuando en la mayoría de los casos ninguno de los dos tiene ganas de hacerlo. La fórmula correcta en tales casos y siempre que no medie invitación especial, es la de que cada cual pague lo que 'haya consumido.

Por último, recordaremos la obligación que tenemos de saludar correctamente a las señoras y caballeros con quien nos crucemos en las escaleras de una casa. Nunca subiremos en ascensor con una señorita sola y desconocida, y, al hacerlo, lo efectuaremos descubriéndonos hasta la salida del camarín y facilitando el acceso de ellas a la escalera. También es obligado ceder el paso a las señoras y personas de respeto cuando nos encontremos con ellas en una escalera".

\section{8. ¿Cómo debe oler un hombre?}

Antonio de Armenteras, en su "Enciclopedia de la Educación y la Mundología" nos enseñaba en 1957 cómo debe de oler un hombre.

Nunca, un perfume será lo suficientemente viril para poder ser usado por un hombre. Esta afirmación no significa de ninguna manera que yo vaya a sostener que el hombre, para ser considerado como tal, deba oler a tabaco o a vino. El que huela así, tal vez sea un hombre, pero un hombre sucio.

El hombre debe oler a limpio, a jabón, o a colonias frescas, cargadas de alcohol y con aromas de limón. Péinese y fricciónese con esa clase de aguas, después de un buen 
lavado, y el olor que despida su presencia, será sumamente agradable sin dejar de ser varonil.

Soy tan enemigo de los perfumes, que tal vez no esté en lo cierto al recomendar a las mujeres que los usen con mucha precaución, o mejor aún que no los usen. [... ] En primer lugar, porque bastará que una dama perfumada nos ofrezca su mano, para que nos traspase el olor de su perfume y lo mismo nos sucederá, si resulta ser nuestra vecina de asiento en el tranvía, en el autobús, en el teatro o en el cine. [...]

\section{El buen niño republicano}

En el libro destinado a formar buenos niños republicanos, se proponen ejercicio de conversación y lectura sobre cultura republicana. Los escolares debían ejercitarse en pruebas como ésta:

¿Cómo se llamó el primer Presidente de la República de 1873? ¿Qué edad tenía Figueras cuando fue elegido Presidente? ¿Cómo era el primer Gabinete de la República? ¿Sabes en qué consiste el Cantonalismo? ¿Cuál fue la conducta de Estanislao Figueras al ver la Patria en peligro?

Explica a tus amigos la biografía de Estanislao Figueras, primer Presidente de la primera República.

\section{Recomendaciones para la conversación y el beso (en la mano)}

No está tan pasada de moda la recomendación que Ezequiel Solana, maestro normal, incluye en su libro "Reglas de urbanidad y buenas maneras. Advertencias útiles, que conviene conocer y practicar a toda persona que viva en sociedad", A propósito de la conversación señala que "Si la palabra es plata, el silencio es oro", dice un proverbio árabe.

Se arrepiente uno frecuentemente de haber hablado mucho; raras veces de haber hablado poco. (Se juzga de un hombre por la. Palabra como de un vaso por el sonido." Por eso conviene hablar poca y saber lo que se habla. Se procurará, cuando se llega a una reunión, no ponerse a hablar sin informarse previamente de lo que se trata. Se cuidará también de no interrumpir inopinadamente, y en todo caso que la interrupción sea breve y oportuna. Sin embargo, está admitida la interrupción cuando sirve para distraer hábilmente la conversación de un terreno peligroso o para. Terminar un asunto suficientemente discutido.

Gertrud Oheim (1956) en el "Abc de la etiqueta moderna" se refiere al beso en la mano de este modo:

Esta costumbre está muy discutida, pero hay que reconocer que es una manera muy galante de saludar a las damas. Tiene muchos enemigos y muchos partidarios.

El besar la mano tiene también sus reglas que habrá que seguir para no caer en el ridículo. Antiguamente sólo se besaba la mano a las mujeres casadas. En la actualidad hay muchas mujeres solteras célebres por haber ganado el premio Nobel, o por ser médicas famosas o pedagogos de mérito, etcétera, a las que se concede el 
mismo privilegio aunque sean solteras. Lo mismo se hace con señoritas ancianas. Porque el besar la mano siempre expresa cierta admiración y respeto.

Ante todo habrá que saber distinguir qué manos merecen ser besadas. Hay hombres que tienen la convicción de que este gesto nunca está de más y lo prodigan sin distingas. Besan las manos en la calle, en el tranvía, en la piscina, etcétera, sin pensar que están haciendo el ridículo y abrumando con esta atención tanto a una dama elegante como a una humilde mujercita que se estará riendo de él para sus adentros. Por lo tanto, si practicamos esta costumbre, debemos hacerla como corresponde.

- Sólo se besará la mano en lugares cerrados, nunca en la calle.

- El caballero se inclinará sobre la mano de la dama, que a su vez la levantará un poco facilitándole el gesto. Pero es de mal gusto levantar bruscamente la mano de la dama o plantarle un beso sonoro.

- En rigor, si la dama lleva guantes no debiera besársele la mano. Sólo en las operetas y en las novelas malas se atreven los caballeros a levantarles el puño del guante para depositar un beso rendido y cursi en su blanca mano. Pero el uso ha extendido el beso al guante.

- Los caballeros con sensibilidad notarán en el acto cuándo una dama desea que le besen la mano o no. Tampoco es femenino obligar a los señores a besar la mano, colocándola a la altura de su boca.

\title{
11. Aquella moral de aquellos tiempos
}

Los alumnos de la comunidad salesiana tuvieron, durante mucho tiempo, que utilizar su propio Manual Urbanidad, llamado "Cortesía Juvenil". Entrados los años sesenta, aprendían cosas como ésta, escrita a modo de exhortación:

\begin{abstract}
"Honestidad entre jóvenes de ambos sexos. Reprueba la actitud poco correcta y a veces desvergonzada de ciertos jóvenes de ambos sexos (igualmente reprobables aunque se digan novios), que se permiten actitudes que hieren la sensibilidad del público correcto, ofenden el pudor de las gentes honestas, dan escándalo a niños y jóvenes y llaman la atención con ademanes groseros y provocativos.

Tal sería echar los brazos sobre los hombros de la persona de otro sexo, ir cogidos de la mano [el subrayado en nuestro], ir medio abrazados y hacer demostraciones afectivas en plena calle, en trenes, metros, coches y cines; en los asientos de los jardines, en las terrazas de los cafés y en las orillas de los caminos y carreteras"
\end{abstract}

\section{Los últimos libros de urbanismo}

Debemos a Fernando Díaz-Plaja alguno de los últimos y más actualizados libros sobre la materia que nos ocupa. Su "Manual de Cortesía y Convivencia" es un libro divertido, de fácil lectura que disecciona y da consejos para evitar los viejos y nuevos malos hábitos de los españoles. A modo de ejemplo, apunta sobre ese interlocutor que siempre tiene que estar tocando a la otra persona: 
El Galateo Español de Gracián Dantisco (1582) ya advertía de la descortesía que significaba estar uno tocando al otro en el transcurso de una conversación. Porque no le ha de estar dando con el codo o con la mano como muchos suelen hacer a cada palabra diciendo: iLo que os digo, ¿no es verdad?, oídme, señor Fulano; y todavía les están sacudiendo con las manos en los pechos y asiéndolos de los botones. $Y$ yo vi a uno que tenía tal manía en esto que desabrochaba a cuantos hablaba!.

No conozco a nadie que haya llegado a ese extremo, pero sí (como seguramente muchos lectores) al tipo que necesita refrendar sus argumentos verbales con el constante toqueteo en el brazo o la pierna del interlocutor. Mi impresión personal es que se trata de una persona tan insegura que teme que a cada instante el oyente se distraiga y no atienda a sus razones, por lo que necesita llamarle la atención de forma constante con los nudillos, como quien golpea una puerta que parece le están cerrando".

Un consejo final, releer estos viejos manuales de vez en cuando nos ayudará a evitar el contagio que supone una sociedad donde ya no se valora como nuestros abuelos el respeto al otro y la cortesía.

Para varias generaciones de españoles, "Corazón" de Edmundo de Amicis, fue el libro de lectura y urbanidad en la escuela

Miles de españoles, ahora sesentones, conservamos el recuerdo del que fue para miles de nosotros el libro de lectura y prontuario por excelencia de reglas de urbanidad en la escuela primaria. El libro, que aparece en Italia en 1886, hizo célebre a su autor, Edmundo de Amicis, en el mundo entero y alcanzó más de cuarenta ediciones ya en su tiempo, siendo traducido a todos los idiomas del mundo

El argumento consiste en un diario escolar, en el que Enrique, muchacho turinés de tercer curso, anota los acontecimientos principales del año, entremezclados con las cartas de sus padres y con cuentos mensuales, algunos de los cuales se han hecho famosísimos. (De los Apeninos a los Andes). Es un libro sentimental, lleno de recuerdos, que exalta el patriotismo, la solidaridad con todos, la generosidad y el altruismo. ¿Y cómo no, la urbanidad?

Veamos uno de los fragmentos que enseña a comportarse en la calle (pero piénsese que estamos en la Italia del Resurgimiento):

......Te observaba desde la ventana esta tarde al volver de casa del maestro; tropezaste con una pobre mujer. Cuida mejor de ver cómo andas por la calle. También en ella hay deberes que cumplir. Si tienes cuidado de medir tus pasos y tus gestos en una casa, ¿por qué no has de hacer lo mismo en la calle, que es la casa de todos? Acuérdate, Enrique: Siempre que encuentres a un anciano, a un pobre, a una mujer con un niño en brazos a un impedido que anda con muletas, a un hombre encorvado bajo el peso de su carga, a una familia vestida de luto, cédeles el paso con respeto: debemos respetar la vejez, la miseria, el amor maternal, la enfermedad, la fatiga, la muerte. Siempre que veas una persona a la cual se le viene encima un carruaje, quítale del peligro, si es un niño; adviértele, si es un hombre; pregunta siempre qué 
tiene al niño que veas solo llorando. Recoge el bastón al anciano que lo haya dejado caer. Si dos niños riñen, sepáralos; Si son dos hombres, aléjate por no asistir al espectáculo de la violencia brutal que ofende y endurece el corazón. Y cuando pasa un hombre maniatado entre dos guardias, no añadas a la curiosidad cruel de la multitud la tuya; puede ser un inocente. [...]

[...]Responde siempre con finura al que te pregunte por una calle. No mires a nadie riendo, no corras sin necesidad, y no grites. Respeta la calle. La educación de un pueblo se juzga, ante todo, por el comedimiento que observa en la vía pública. Donde notes falta de educación fuera, la encontrarás también dentro de las casas. Estudia las calles estudia la ciudad donde vives, que si mañana fueras lanzado lejos de ella, te alegrarías de tenerla bien presente en la memoria y de poder recorrer con el pensamiento tu ciudad, tu pequeña patria, la que ha constituido por tantos años tu mundo, donde has dado tus primeros pasos al lado de tu madre....."

\section{Los tratamientos y su historia}

Afirma el profesor Juan Raposo (2003: 95 y ss), de la Universidad de A Coruña que se ha dicho siempre de los españoles que era consustancial con ellos la cortesía en el trato, así el Emperador Carlos V decía que "Ios alemanes hablaban como carreteros, los ingleses como niños, los italianos como enamorados, los franceses como amos y los españoles como Reyes". Estudioso y profundo conocedor de toda la bibliografía existente al respecto, recuerda que Título XII, Libro VI de la Novísima Recopilación, habla extensamente de los tratamientos de palabra y por escrito.

El Rey Felipe II, escribió al respecto los siguientes versos: "si es nada, la cortesía,/Menos que el aire y el viento/El que de ella es avariento/¿De que liberal sería?/La grandeza más honrada/Que los príncipes tenemos/Es que dar mucho podemos/Á todos con lo que es nada".

Frente a la vulgaridad de nuestro tiempo, proclama Raposo que

"el uso de los tratamientos, y la corrección en los mismos, es sinónimo de urbanidad y cortesía, favorece las relaciones sociales y administrativas, y en última instancia, entiendo que hace más fácil la vida, y colma a veces, el sano orgullo de quien desempeña un cargo o una actividad representativa, constituyendo un motivo de distinción para quien lo recibe sin que suponga carga alguna para el erario público".

\section{Tratamientos desaparecidos por la fuerza de los hechos}

En el libro "Curso Superior de Comunicación y Protocolo", del que tuve el honor de ser editor, se refiere Raposo a la serie de usos y tratamientos tradicionales de España. A saber:

Muy Alto

Poderoso

Ínclito

Perínclito 
Pariente Mayor

Ciudadanos Honrados

Hombre bueno

Y con evidente sentido del humor añade que desaparición la de éstos dos últimos títulos, que no sabemos si es debida a la evolución de las costumbres o a la de las personas portadoras de aquéllas.

\section{La Casa Real}

Raposo analiza el origen de los tratamientos de los miembros de la Casa Real: Majestad y Alteza

En cuanto al primero, el de "majestad", siguiendo al Barón Pujol de Planes, en su magnífica, y hoy prácticamente inencontrable obra "Monitorio Aúlico" que utilizare para desarrollar este apartado, dice que nos encontramos ante un tratamiento que corresponde a "... Dios, á su Madre Purísima y también a los Emperadores y Reyes. Equivale a celestial en el sentido de elevación, grandeza y excelencia, sublimidad de alguna persona ó cosa. Este tratamiento insuperable se dio en la antigüedad á los Reyes y Príncipes de la sangre". Continúa el autor citado explicando que éste término de "Majestad" significa "..., bondad, dignidad, poderío, magnificencia, pompa, ostentación, aparato imponente y majestuoso con que se ejecuta alguna cosa". Dice que tal tratamiento se corresponde con una divinidad mitológica, "... hija del Honor y diosa de la Reverencia", y se atribuye a Ovidio que tal divinidad reinaba en el cielo, y que gobernó el mundo desde el Caos. Para Pujol de Planes la antigüedad de la expresión es manifiesta. Horacio, cuando dirigió la palabra a Cesar Augusto, le da el título de Majestad en la primera epístola de su segundo libro. En España se da este tratamiento a los Reyes ya en un documento del siglo XIII, en concreto en la causa que se siguió al Vizconde de Cardona y a sus defensores por haberse rebelado contra su soberano, Don Pedro el Grande, Rey de Aragón;

El tratamiento significó originariamente la dignidad del pueblo romano, después fue utilizado por los Emperadores y varios representantes del pueblo conforme a la Lex Regia, de ahí que fueran denominados como "Majestas Augusta" y "Regia Majestas". También en alguna ocasión los Papas han utilizado tal tratamiento. Carlos V lo impuso en toda España, y a partir de su uso por tal monarca, se extendió a los posteriores (los antecesores de este Rey, sobre todo los monarcas de Castilla utilizaban el tratamiento de Alteza). También disfrutaron de este tratamiento ciertos Tribunales de Justicia, caso del Consejo Real de Navarra. Por Decreto de las Cortes de 19 de abril de 1814, en concordancia con el artículo 169 de la Constitución, se declara que el tratamiento de "Majestad" corresponde exclusivamente al Rey.

El término "Majestad" es equivalente a "Sire", tratamiento propio de los monarcas de Francia, aunque también es empleado en Inglaterra, y en otros reinos europeos.

En cuanto al de Alteza, Raposo señala que su origen se halla en etapas finales del Imperio Romano donde se aplicaba a los Obispos. 
En los siglos XIII, XIV y XV se daba este tratamiento a los monarcas de los reyes cristianos, $y$ en general, a aquellos que se consideraban como vasallos del Sacro Imperio Romano. A partir de Carlos $V$ este tratamiento se aplicaba a los Príncipes herederos, a los infantes e hijos y hermanos de reyes, a sus hijos, consortes y a algunos magnates. Posteriormente a Felipe IV se agregaron al apelativo de Alteza los adjetivos Real, Imperial y Serenísima. En la Ley 1a , Título XII, Libro VI de la Novísima Recopilación, que es la Pragmática de Felipe IV, de 7 de agosto de 1636, se indica que "... cuando se dijere y escribiere absolutamente á Su Alteza, se ha de atribuir sólo á el Príncipe heredero". Es de destacar que el tratamiento tradicional de los Cardenales de la Iglesia Católica, cuando eran príncipes de sangre real, era el de "Alteza Eminentísima", y si era Arzobispo, Obispo o Presbítero, su tratamiento era el de "Vuestra Alteza Reverendísima".

Por otra parte las altas dignidades de Castilla se les dio en la antigüedad el tratamiento de "Alteza". Hoy no se da, como veremos, el tratamiento dicho tratamiento más que al Príncipe de Asturias, a los Infantes y a los Príncipes Imperiales o Reales extranjeros, y a los llamados de la sangre.

\section{Excelentísimo e Ilustrísimo}

Decía Napoleón que "gobernar es establecer prioridades". La decisión del gobierno de José Luis Rodríguez Zapatero de suprimir los tratamientos a las autoridades públicas constituyó una prueba de que en el gabinete socialista, presidido por José Luis Rodríguez Zapatero, durante su mandato no siguió aquella máxima del magnífico corso. No parecía que entre los problemas más apremiantes del país figurara precisamente esta cuestión, ni que fuera una de las pesadillas que quitara el sueño a los ciudadanos que se mantuvieran estos viejos usos y fórmulas en el lenguaje protocolario. Pero la decisión tuvo una trascendencia jurídica, histórica y cultural que requiere algunas reflexiones previas para concluir que, a nuestro entender, fue innecesaria, inútil y ineficaz, y que va a produjo una serie de efectos en cadena que afectaron a arraigadas tradiciones que constituyen corpus y sustancia de numerosas instituciones públicas. Al final, las cosas siguieron como estaban y los tratamientos indicados se siguen usando, aunque de modo no uniforme

La revisión -a la baja- que se vino haciendo en España o sobre el entramado institucional constituyó en realidad el desmantelamiento de espacios de representación cultural que afecta a tradiciones, símbolos, efemérides, usos y costumbres que son la urdimbre de nuestra propia personalidad colectiva, de nuestras peculiaridades más específicas. Y estos bienes culturales se están suprimiendo a cambio de nada. Ora se reforma un escudo de armas de una institución para agradar a un colectivo minoritario, desposeyendo de sentido un determinado emblema; ora se retira una estatua de la iconografía tradicional española, ya se deja de celebrar una fiesta popular o se le da la vuelta al sentido que tradicionalmente poseía.

Como dice el doctor Juan Raposo, especialista en estas materias, a las que lleva dedicado largos años de estudio: "El uso de los tratamientos, y la corrección en los mismos, es sinónimo de urbanidad y cortesía, favorece las relaciones sociales y administrativas, y en última instancia, entiendo que hace más fácil la vida, y colma a veces, el sano orgullo de 
quien desempeña un cargo o una actividad representativa, constituyendo un motivo de distinción para quien lo recibe sin que suponga carga alguna para el erario público".

La decisión del Gobierno Zapatero de suprimir en su día los tratamientos honoríficos a las autoridades de la Administración General del Estado (El propio presidente del Gobierno y sus ministros dejaron oficialmente de ser excelentísimos señores o excelentísimas señoras, y habría que llamarles simplemente señor o señora) abrió un curioso debate en el que los autores de la medida no habían caído. Es de suponer que poco a poco, la norma se iría extendiendo al resto de las instituciones. Si se suprime el tratamiento augusto a un ciudadano común que, por ejemplo, ha llegado a ser diputado, porque sus conciudadanos lo han elegido para representarlos, ¿qué hacemos con los tratamientos asociados a los títulos nobiliarios o a la misma Familia Real? Lo congruente será suprimirlos también siguiendo el mismo razonamiento lógico. ¿Y con sus señorías los jueces"

"El Código para el Buen Gobierno del Gobierno", además de estar mal redactado y de confundir el sexo de las personas con el género de las palabras, fue un prontuario de buenas intenciones, cuya aplicación, en la parte realmente magra, precisaría más concreción jurídica. Es de destacar, pues, que lo se suprimía -como medida modernizadora- son los tratamientos honoríficos de quienes reciben el tratamiento como consecuencia de haber sido designados para ocupar un cargo en la Administración del Estado, los que son nombrados por un gobierno, cuyo presidente ha tenido que recibir previamente la confianza de la cámara donde reside la soberanía de la nación. Pero nada afecta tal medida de otros tratamientos todavía de menor justificación, como quienes heredaron un título por ser simplemente hijos de su padre.

Volvamos a Raposo:

Cabe recordar que en España, los tratamientos más usados para dirigirse a las autoridades eran "Excelentísimo" e "Ilustrísimo". Como explica Raposo, el término "Excelentísimo", constituye un tratamiento de cortesía, que gramaticalmente merece la consideración de superlativo del adjetivo "excelente". Significa la cualidad de lo excelente en sumo grado que tienen los o se atribuye a los espíritus celestiales. Dicho tratamiento es aplicable a personas o Corporaciones (de generalizado uso en la Administración Local, y comenzó a utilizarse a principios del siglo XVI para designar a los Grandes de sangre real. La Ley 1a , Título XII de la Novísima Recopilación, en su artículo 11 dice que este tratamiento "... es el mayor que permitimos á la más elevada esfera y el más distintivo en nuestros dominios". En cuanto a su utilización, va acompañado de "Señor" y del "Don", tratándose de nombres, y sin el "Don", y aún sin el "Señor", refiriéndose a Títulos del reino. Tiene como variantes las de "Vuecencia", "Su Excelencia" y "Excelencia".

"Ilustrísimo" es superlativo de llustre. Se aplica a las personas de elevada categoría. Se asocias con nobleza esclarecida, insigne, célebre: Desde el siglo XIII ya estaba en uso en España dándose originariamente a los Emperadores y a los Reyes en el Reino de Aragón, y extendiéndose posteriormente a los Virreyes, Arzobispos, Grandes, Titulados y Señores Jurisdiccionales, hasta el punto de que era considerado de mayor dignidad que el de "Excelentísimo", que posteriormente ha sido tenido en superior categoría. Así, Gaspar de Texeda dice que "A los grandes de España, Condestable, Almirante, y todos los duques, marqueses, y condes de alto estado; siempre llustrísimo, y á los demás 
señores no tan grandes, Muy llustre". Este tratamiento va seguido siempre de "Señor", y de "Don", si se refiere a nombres de personas, desapareciendo el "Don" al designarse algún título, dignidad eclesiástica ó cargo oficial o de honor.

En el "Manual de estilo del lenguaje administrativo" (Ministerio para las Administraciones Públicas, Madrid, 1990) pp. 143-144 se señala que:

\begin{abstract}
"A pesar de las disposiciones oficiales que proscriben el uso de tratamiento personal en la Administración Pública (Orden Ministerial de julio de 1986, publicada en el Boletín Oficial del Estado del 22 de julio), la pervivencia de estos usos en los documentos constituye un fenómeno curioso que demuestra hasta qué punto existe una fijación social en la acuñación y el uso de estas fórmulas. Por consiguiente, parece adecuado recomendar a aquellas personas que se relacionen con funcionarios públicos en el desempeño de sus puestos de trabajo la supresión de toda clase de tratamientos personales de carácter honorífico, desde Director General para abajo en la escala jerárquica, anteponiendo a la denominación de su empleo o cargo la fórmula normal de SEÑOR (Sr. Director General; Sr. Jefe de Sección...), lo que refuerza de manera simbólica la idea de que los puestos de trabajo en la administración pública no poseen un carácter reverencial, sino que están servidos por hombres y mujeres a los que la colectividad remunera para que presten el mejor servicio posible a los ciudadanos y a los que hay que dar un trato normal de cortesía en consonancia con los modos sociales actuales."
\end{abstract}

En este caso, parece que se confunden las cosas: una son los funcionarios públicos que ejercen un trabajo en la Administración del Estado, y otras las autoridades que representan a las instituciones $y$, particularmente, constituyen el órgano colegial donde reside la soberanía nacional que antes o después se verá alcanzado por esta ola de modernidad que ha lanzado la Moncloa sobre el país. Conservar estos tratamientos honoríficos era una forma más de mantener una vieja tradición española. Cierto que la medida afecta solamente, de entrada, a los altos cargos de la Administración General del Estado, pero es fácil deducir que por coherencia o analogía antes o después alcanzará a todos los demás cargos que hoy conservan y ostentan alguna clase de tratamiento honorífico y protocolario. ¿Servirá todo esto para que el aparato del Estado funcione mejor y los españoles seamos más felices?

\title{
17. El tratamiento de Señoría
}

Para jueces, diputados y miembros del claustro universitario en sesión solemne se emplea el tratamiento de "Señoría". Como señala Raposo, indica en origen dominio, imperio o mando de algún estado nacional, "como las Señorías de Génova y Venecia, y los territorios jurisdiccionales que eran gobernados por Duques, Marqueses, Condes, etc. La palabra "Señoría" tiene además la acepción de superior jerárquico":

Este tratamiento se dio a los Emperadores y en España empezó a usarse en tiempo del Rey Don Enrique III, y se daba no sólo a los Infantes, sino también a los Reyes de Castilla, casi siempre precedido del epíteto "Gran". Se utilizaba también anteponiéndolo al nombre de Ciudades, Corporaciones y, en el siglo XIX, a algunas Cámaras Constitucionales y a sus representantes. Los Grandes de España, ante su 
Santidad, gozaban del derecho a asiento en banco raso, siendo tratados por el Supremo Pontífice como "Señorías". Hasta tal punto se tenía en consideración este tratamiento, que el propio Sancho Panza decía a su mujer: "si Dios me llega a tener algo que de gobierno, que tengo que de casar á Mari-Sancha tan altamente, que la alcancen sino con llamarla Señoría".

Este tratamiento se usa anteponiéndole las palabras "Vuestra" y "Su", excluye el de "Señor", pero exige el de "Don" para los nombres, y alterna de palabra y por escrito con el de Usía,

Es este, el de "Usía" un tratamiento que en no pocas ocasiones se ha empleado erróneamente, y sobre el que existe una cierta confusión. En principio fue apocope de "Vuestra Señoría" y "Vueseñoría". Alterna por escrito y de palabra esta cortesía de jerarquía y de palabra con los tratamientos de Señoría Ilustrísima, Ilustrísimo Sr., y señoría.

En el ámbito militar, según el grado, se usan estos tratamientos:

General o almirante: Excelentísimo Señor, Su Excelencia o Vuecencia

Coronel o capitán de Navío: Ilustrísimo Señor o Usía.

\section{Señor, Don y Usted}

Con respecto a los usos más comunes, Señor, Don y Usted, su historia no desmerece de otros tratamientos de más alcurnia.

Señor es el nombre que por antonomasia damos los católicos a Dios, y a Jesucristo, a quien en nuestras plegarias y oraciones denominamos "Nuestro Señor".

A los Emperadores, Reyes, Principes, etc, se les dio de palabra y por escrito este tratamiento, que en su origen proviene de "Senior", que etimológicamente significa "el más viejo", en contraposición a "junior" o más joven. En Vizcaya la más alta jerarquía de dicho territorio histórico, el Señorío de Vizcaya, recibía el título de Señor. La voz "Señor", aparece en numerosas lenguas: herrn, sir, lord, signore, sire, senhor, monsieur, micer, mosén. Para algunos deriva del hebreo "sar" que significa persona distinguida, otros lo hacen proceder del griego "Kurios, Señor", o del latín "senior", algunos incluso mencionan la posibilidad que era el tratamiento que se daba a los primeros faraones, entre los cuales "Si-re" equivalía a hijo del sol

Apunta Raposo que la voz "Señor" ha traspasado su origen y es sinónimo de noble, decoroso, digno y nos remite a una actuación significada por la educación, distinción y modales de quien la realiza.

En cuanto a su empleo cabe decir que como término de urbanidad precede a los Títulos del reino; cuando no lleva subsiguientemente el de Don, precede a los apellidos, títulos, dignidades y cargos, y así se dice, Sr. López, señor doctor, señor Alcalde. Además los títulos de excelentísimo, ilustrísimo, etc., llevan pospuesto el calificativo de Señor. Cabe por ultimo decir que hoy es un término de cortesía aplicable en toda relación social.

Siempre recordaré que cuando aprobé la Reválida de Cuarto, mi abuela me dijo que ya podía usar el tratamiento de Don. Pese al uso que compartimos con los italianos, como dice Raposo, referido a su caso, evocando novelas o películas de mafiosos, en materia de 
tratamientos, nos cabe el honor a los españoles de ser sus inventores, aplicándose originariamente a los Papas, de donde pasó a los Obispos, Abades y otras dignidades de la Iglesia, extendiéndose después a los monjes.

"Don" es un término polisémico, que en una de sus acepciones significa cualquiera de las cualidades morales que embellecen, adornan o enriquecen al hombre; etimológicamente, viene del latín "dominus", que significa dueño de casa y señor, en contraposición al esclavo. El primer monarca que usó el Don, fuer Rodrigo, rey godo, al que siguieron los reyes de León y Castilla. Era un título puramente personal, y por eso en las cartas reales y privilegios rodados que confirmaban los más grandes señores de los reinos españoles, aparecen firmados con tal dignidad por algunos y otros sin ella. Fue tan considerado en el siglo XV el título de "Don" que muchas personalidades de distinguida representación y elevada jerarquía, que por sus dignidades y empleos disfrutaban de tratamientos tales como "Magnífico", "Muy Noble" y "Señor", carecían del título de "Don", que inicialmente sólo se confería en propiedad por los reyes a los duques, condes y marqueses, por concesión que iba unida a la de esos títulos de dignidad y nobleza. La gracia real para poder usar ese tratamiento era un dictado de honor, a modo de título de la última categoría, hasta el punto de ser considerado como título más que como tratamiento. Desde el siglo XVII se empieza a generalizar tal tratamiento, como reseñó Quevedo en su "Visita de los chistes", diciendo que en todos los oficios, artes y estado se introdujo el Don en hidalgos y villanos, y hoy en día se aplica a todo el mundo sin distinción.

En cuanto al "Usted" procede de "Vuesa Merced". Dice Raposo que su usó llegó a estar regulado normativamente y así en el Reglamento Orgánico de la Carrera Diplomática vigente a principios del siglo XX, se daba el tratamiento de "usted" a los Secretarios de 2 a y 3 a clase de tal carrera, así como a los Agregados Diplomáticos, y también aparecía tal tratamiento en el Reglamento de la Carrera Consular. Hoy es un modo de tratamiento de cortesía y respeto hay en decadencia debido a la extensión de la vulgaridad y el tuteo.

\section{BIBLIOGRAFÍA}

AGUILERA, Alfredo (1980): Buques de Guerra Españoles, 1885-1971. Editorial San Martín, Madrid.

AMABLE, Angel (1992): Manual de las buenas maneras. Círculo de Lectores, Madrid.

AREILZA, José María (1980): Prólogo a Buques de Guerra Españoles, 1885-1971. Alfredo Aguiilera: Editorial San Martín, Madrid.

AZUSTRE, Juan Antonio y CASAS, Juan (1997): Manual de Retórica. Ariel, Barcelona.

BALDI, Camillo (1997): El lenguaje secreto del rostro. Editorial de Vecchi S.A.,Barcelona.

BLANCO AMOR, Eduardo (1983): Las buenas maneras. Edicións Xerais de Galicia, Vigo.

BROWYN, COSGRAVE (2005): Historia de la moda. Desde Egipto hasta nuestros días. Gustavo Gili, Barcelona.

CALLIERES de, François (2001): Negociando con príncipes. Edición de Attillion Locatelli. Biblioteca la Esfera, Madrid. 
CALVET de MAGALHAES, José (2001): Manual diplomático. Direito diplomático. Prática diplomática. Editorial Bizáncio, Lisboa

CAPRIOTTI, Paul (1999): Planificación estratégica de la imagen corporativa. Barcelona, Ariel.

CASTRO, Américo (Reedición 1996): España en su historia: cristianos, moros y judíos Grijalbo. Barcelona.

CASTRO, Américo (1975, Sexta edición): "La realidad histórica de España“. Editorial Porrúa. México.

CHÁVARRI del RIVERO, Tomás (2004): Protocolo internacional. Ediciones Protocolo, Madrid.

CHAVES, Norberto (1994): La imagen corporativa. Teoría y metodología de la identificación institucional' - Gustavo Gili.Dondis, D.A, México

DAVIS, Flora (2002): La comunicación no verbal. Alianza Editorial, Madrid.

DETIENNE,Marcel (1979): Pratiques culinaires et esprit de sacrifice, en: M. Detienne et J.-P. Vernant: La cuisine de sacrifice en pays grec; Gallimard, Paris

MAISONNEUVE, Jean (2003): Os rituais. RES-Editora, limitada, Oporto.

FERNÁNDEZ PULPEIRO, Juan Carlos (2006): Civilidad. Servicio de Publicaciones de la Diputación Provincia. Lugo.

FLOWER, Sibylla Jane y otros (1984): "Debrett". Nuevo tratado de Etiqueta y reglas sociales, (edición española). Edaf, Madrid.

FUENTE LAFUENTE, Carlos: (2006). Protocolo oficial: las instituciones españolas del Estado y su ceremonial.Ediciones Protocolo, Madrid.

GALINO, Francisco (1999): Protocolo y Ceremonial Universitario y Complutense. Editorial Complutense, Madrid,

GRACIÁN, Baltasar (2002): El arte de la prudencia, edición da José Ignacio Díaz Fernández. Ediciones Temas de hoy (vigésima edición), Madrid.

ILLAFAÑE, Justo (1993): Imagen positiva. Gestión estratégica de imagen de las empresas. Ediciones Pirámide, Madrid.

LÓPEZ NIETO y MALLO, Francisco (2005): Manual de Protocolo. Ariel, Madrid.

MARÍN CALAHORRO, Francisco (2000): Comunicación y Protocolo. Los medios en los actos oficiales. Bayer Hermanos, Barcelona.

MARSÁ, Francisco (1986): Diccionario normativo y guía práctica de la lengua española. Ariel Lingüística, Barcelona.

MARTÍNEZ de SOUSA, Javier de (1993): Diccionario de redacción y estilo. Pirámide, Madrid. MIGUEL, Amado de (1991): Cien años de urbanidad. Crítica de las costumbres de la vida española. Planeta, Barcelona

MONTANELLI, Indro (1964): Historia de los romanos. Plaza y Janés, Barcelona 
MORTASA GARAVELLI, Bice (1998): Manuel de retórica. Cátedra, Madrid.

OTERO ALVARADO, María Teresa (2000): Teoría y estructura del Ceremonial y el Protocolo. Mergablum, Sevilla.

PAOLI, Ugo Enrico (1944) (traducción: I. Farrán y Mayoral): “URBS”. La vida en la Roma antigua (URBSnVita Romana), autor: Ed. Iberia-Joaquin Gil-Muntaner, 180- Barcelona, PULPEIRO, Juan Carlos (1995) Buenas costumbres, modales y protocolo. Lugo Diputación Provincial de Lugo.

RAMOS, Fernando (2002): La comunicación corporativa e institucional. De la imagenal protocolo. Madrid. Editorial Universitas, Madrid.

(2003): Curso Superior de Comunicación y Protocolo. Luis Fernando Ramos Fernández (editor), Universidad de Vigo, Extensión Universitaria. Vigo.

(2007): El protocolo universitario. Historia, tradiciones y práctica actual del ceremonial en la Universidad española. Vigo. Consello Social de la Universidad de Vigo.

(2007) Protocolo y estrategia para las Pymes. La imagen y la excelencia de los pequeños. Netbiblo, A Coruña.

(2007): Estratégias e Protocolo para a Comunicaçao Corporativa. Um valor acrescentado para empresas e instituiçôes. Media XXI, Formalpress, Lisboa.

(2008) El protocolo de empresa. Herramientas para crear valor. La Coruña. Editorial Netbiblo/Instituto Tecnológico Empresarial, A Coruña.

(2010): Comunicación y Protocolo en el espacio local. Imagen y transparencia de las instituciones públicas. Servicio de Publicaciones de la Diputación de Pontevedra, Vigo.

Estudios de Comunicación y Protocolo (I) [Editor y coautor] (2010): Universidad de Vigo. Cursos Complementarios. Vicerrectorado de Formación e Innovación Educativa. Área de Periodismo. Sección Departamental de Comunicación. Departamento de Psicología Evolutiva Comunicación, Vigo-

(2013); Protocolo oficia, sociedad civil e instituciones. Las autoridades públicas en los actos corporativos y de empresa. Editorial Académica Española, Alemania.

(2013) Protocolo y relaciones públicas en la sociedad pluralista. Usos, normas y reglas en los actos públicos y privados (en colaboración con José Daniel Barquero y Manuel Medina Elizondo). Fundación ESERP-Furtwangen editores, Barcelona.

RAPOSO, Juan (2003): "Los tratamientos en el ordenamiento jurídico español" y "La necesidad de protocolo específico pafra la Comunidad autónoma de Galicia" en Curso Superior de Comunicación y Protocolo. Luis Fernando Ramos Fernández (editor), Universidad de Vigo, Extensión Universitaria. Vigo.

REINER, Brehler (1997): Prácticas de oratoria moderna. Jesús Domínguez Editor, Madrid.

RODRÍGUEZ ENNES, Luis: (2003): “Apuntes históricos en torno a la evolución del Protocolo desde la Roma Imperial al final del Antiguo Régimen con alguna referencia a Galicia " en 
Curso Superior de Comunicación y Protocolo. Luis Fernando Ramos Fernández (editor), Universidad de Vigo, Extensión Universitaria. Vigo.

SÁNCHEZ ALBORNOZ, Claudio (1976. 5a edición. Dos tomos): España un enigma histórico. Hispano Americana S.A. Barcelona.

SAPIR, Edward (1931): Fashion, volumen 6 en Escyclopaedia of the Social ScienciesMcMillan, Nueva York

SIMMEL, George (1957): Fashion en American Journal of Sociology, número 62 URBINA, José Antonio (1994). El protocolo en los negocios. Temas de hoy, Madrid. VALLEJO NÁGERA, Juan Antonio (1990): Aprender a hablar en público. Planeta, Barcelona.

VERNANT, Jean-Pierre Vernant (1979): À la table des hommes, en: M. Detienne et J.-P. Vernant: La cuisine de sacrifice en pays grec; cit., pp. 37-132.

VIEIRA CANNA DE ANDRADE, Elisabete (2001) "Gestos. Cortesía. Etiqueta. Protocolo". Texto Editora Lta. Lisboa.

VILARRUBIAS, Felio (2000): Tratado de Protocolo de Estado e Internacional. Nobel. Oviedo. VILLAFAÑE, Justo (1993): Imagen positiva. Gestión estratégica de imagen de las empresas. Pirámide, Madrid.

VV.AA, 1997): “España. Reflexiones sobre el ser de España“. Real Academia de la Historia. Madrid 